\title{
Anxiety, depression and school absenteeism in youth with chronic or episodic headache
}

\author{
Céline Rousseau-Salvador PhD, Rémy Amouroux PhD, Daniel Annequin MD, Alexandre Salvador MD MSc, \\ Barbara Tourniaire MD, Stéphane Rusinek PhD
}

C Rousseau-Salvador, R Amouroux, D Annequin, A Salvador, B Tourniaire, S Rusinek. Anxiety, depression and school absenteeism in youth with chronic or episodic headache. Pain Res Manag 2014;19(5):235-240.

BACKGROUND: Chronic daily headache $(\mathrm{CDH})$ in children has been documented in general and clinical populations. Comorbid psychological conditions, risk factors and functional outcomes of $\mathrm{CDH}$ in children are not well understood.

OBJECTIVES: To examine anxiety and depression, associated risk factors and school outcomes in a clinical population of youth with CDH compared with youth with episodic headache $(\mathrm{EH})$.

METHODS: Data regarding headache characteristics, anxiety, depression and missed school days were collected from 368 consecutive patients eight to 17 years of age, who presented with primary headache at a specialized pediatric headache centre.

RESULTS: A total of 297 patients (81\%) were diagnosed with EH and 71 were diagnosed with $\mathrm{CDH}$. Among those with $\mathrm{CDH}, 78.9 \%$ presented with chronic tension-type headache and $21.1 \%$ with chronic migraine (CM). Children with $\mathrm{CDH}$ had a higher depression score than the standardized reference population. No difference was observed for anxiety or depression scores between children with $\mathrm{CDH}$ and those with $\mathrm{EH}$. However, children with CM were more anxious and more depressed than those with chronic tension-type headache. Youth experiencing migraine with aura were three times as likely to have clinically significant anxiety scores. Headache frequency and history were not associated with psychopathological symptoms. Children with $\mathrm{CDH}$ missed school more often and for longer periods of time.

CONCLUSIONS: These findings document the prevalence of anxiety, depression and school absenteeism in youth with $\mathrm{CDH}$ or $\mathrm{EH}$. The present research also extends recent studies examining the impact of aura on psychiatric comorbidity and the debate on CM criteria.

Key Words: Adolescents; Anxiety; Children; Chronic headache; Depression

$\mathrm{C}$ hronic daily headache $(\mathrm{CDH})$ is characterized by the presence of primary headache on at least 15 days per month for $>3$ consecutive months without an identifiable organic cause (1). The concept of $\mathrm{CDH}$ is now widely accepted, despite the fact that it remains a general description that does not correspond to a specific clinical diagnosis referenced in the International Classification of Headache Disorders (ICHD-II). $\mathrm{CDH}$ is a term used to define a type of headache that includes chronic migraine $(\mathrm{CM})$, chronic tension-type headache (CTTH), new daily persistent headache and hemicrania continua (1). Episodic headache $(\mathrm{EH})$ is characterized by the presence of primary headache - episodic migraine (EM) or episodic tension-type headache (ETTH) - that do not meet the criteria of CDH (ie, $<15$ days per month for $>3$ consecutive months) $(2,3)$.

While CDH in children is not yet well understood, it is a relatively common condition. Population studies involving children and

\author{
L'anxiété, la dépression et l'absentéisme \\ scolaire chez les jeunes ayant des céphalées \\ chroniques ou épisodiques
}

HISTORIQUE : Les céphalées chroniques quotidiennes (CCQ) sont attestées dans les populations générale et clinique. On comprend mal les problèmes psychologiques comorbides, les facteurs de risque et les résultats fonctionnels des CCQ chez les enfants.

OBJECTIFS: Les chercheurs ont comparé l'anxiété et la dépression, les facteurs de risque connexes et les résultats scolaires d'une population clinique de jeunes ayant des CCQ à ceux de jeunes ayant des céphalées épisodiques (CÉ).

MÉTHODOLOGIE : Les chercheurs ont colligé les données relatives aux caractéristiques des céphalées, à l'anxiété, à la dépression et aux journées d'école manquées chez 368 patients consécutifs de huit à 17 ans qui ont consulté dans un centre spécialisé en céphalées pédiatriques à cause de céphalées primaires.

RÉSULTATS : Au total, 297 patients (81\%) ont obtenu un diagnostic de CÉ et 71, un diagnostic de CCQ. Chez ceux ayant des CCQ, 78,9\% présentaient des céphalées de tension chronique et $21,1 \%$, des migraines chroniques (MC). Les enfants ayant des CCQ présentaient un indice de dépression plus élevé que la population de référence standardisée. Les indices d'anxiété et de dépression des enfants ayant des CCQ ne différaient pas de ceux des enfants ayant des CÉ. Cependant, les enfants ayant des CÉ étaient plus anxieux et plus déprimés que ceux ayant des céphalées de tension chroniques. Les jeunes souffrant de migraines avec aura étaient trois fois plus susceptibles de présenter des indices d'anxiété significatifs sur le plan clinique. La fréquence et les antécédents des céphalées ne s'associaient pas à des symptômes psychopathologiques. Les enfants ayant des CCQ manquaient l'école plus souvent et pendant de plus longues périodes.

CONCLUSIONS : Ces observations étayent la prévalence d'anxiété, de dépression et d'absentéisme scolaire chez les jeunes ayant des CCQ ou des CÉ. Elles s'inscrivent également dans le prolongement d'études récentes sur les répercussions des céphalées avec aura sur la comorbidité psychiatrique et sur le débat sur les critères de CÉ.

adolescents indicate a prevalence ranging from $0.2 \%$ to $7.1 \%(4-6)$, with girls being more likely to experience $\mathrm{CDH}$ than boys $(7,8)$. $\mathrm{CDH}$ is a complex, multifaceted syndrome (9), making it one of the most difficult-to-treat headache types in children, in particular due to its overlap with psychopathology (10). Anxiety and depressive symptoms are the most frequent comorbid conditions (2,11-13). Slater et al (14) observed that $29.6 \%$ of $\mathrm{CDH}$ youth met criteria for at least one current psychiatric diagnosis. A study involving the general population demonstrated a strong association between $\mathrm{CDH}$ and suicide risk (20\%) in adolescents 12 to 15 years of age, who were found to have at least one anxiety or depressive disorder in $47 \%$ of cases (15). In addition, the presence of aura, a neurological phenomenon often associated with migraine, is described as a major predictor of comorbid anxiety and depression $(15,16)$. The prevalence of psychiatric comorbidity can reach $90 \%$ in adults with $\mathrm{CDH}$ (17). This comorbidity may predict the

Hôpital Armand Trousseau, Service d'Hématologie et d'Oncologie Pédiatrique, Paris Cedex 12, France

Correspondence: Céline Rousseau-Salvador, Hôpital Armand Trousseau, Service d'Hématologie et d'Oncologie Pédiatrique, 26 Avenue du docteur Arnold Netter, 75571 Paris Cedex 12, France. Telephone 33-1-71-73-86-26, fax 33-1-44-73-65-73, e-mail celine.rousseau77@gmail.com 
persistence of $\mathrm{CDH}(3,13)$, especially if it is present early in the patient's illness (18). Psychiatric comorbidity with headache also has functional consequences. In one study, an association was observed between depression scores and school absences caused by CDH (19).

In children and adolescents, $\mathrm{CDH}$ significantly impairs quality of life $(12,20)$. Specifically, $\mathrm{CDH}$ is associated with learning disabilities (21), school absenteeism (22) or dropout (10), impaired activities of daily living (11) and sleep disorders (23). Thus, $\mathrm{CDH}$ has important psychological consequences, but also economic repercussions because children with $\mathrm{CDH}$ are more likely to consult specialists than children with $\mathrm{EH}(18,24)$.

To our knowledge, only one clinical population study involving children with $\mathrm{CDH}$ has been conducted in France that examined nonspecific psychiatric comorbidity and risk factors associated with this population (8). This population, however, is reported to account for $5.8 \%$ to $40 \%$ of neurology consultations $(3,20)$. The high prevalence of pediatric $\mathrm{CDH}$ patients indicates that new treatment challenges are emerging. Risk factors need to be identified to provide better-adapted treatment plans and to avoid perpetuating the illness. Several studies involving adults indicate that the presence of headache or $\mathrm{CDH}$ was initially reported in childhood $(25,26)$. These data indicate that, in a clinically significant number of children, $\mathrm{CDH}$ does not improve over time or disappear (27). Charles et al (28) suggest that patients with a high risk for $\mathrm{CDH}$ should be targeted early and intensely for prevention and treatment.

The objectives of the present study were to describe the pediatric $\mathrm{CDH}$ population, to examine the presence of comorbid anxiety and depressive symptoms, to investigate the risk factors associated with $\mathrm{CDH}$ and with psychiatric comorbidity and, finally, to assess the influence of $\mathrm{CDH}$ on school attendance. The data regarding children with $\mathrm{CDH}$ were compared with data regarding children with $\mathrm{EH}$.

\section{Participants and procedure}

\section{METHODS}

From September 2007 to July 2008, 617 consecutive new patients were seen at the Children's Migraine Center (Centre de la Migraine de l'Enfant [CME], Paris, France). The centre is part of an outpatient pediatric pain management unit.

Before the medical consultation, the child and parent received a headache diary in the mail to be completed for approximately three months, which was the average length of time between scheduling an appointment and the date of the appointment. At the first appointment at the CME, the family was seen by a pediatric headache specialist who conducted a semistructured medical interview using a standardized questionnaire based on the ICHD-II criteria. A physical examination was also performed. An additional neurological examination was conducted, as well as brain imaging when necessary, to rule out secondary headache.

To be included in the study, children had to be between eight and 17 years of age, visiting the CME for the first time and presenting with a diagnosis of primary headache according to ICHD-II criteria (1) and the more recent appendix for CM (29).

Patients with headache were classified into four diagnostic categories: EM (code 1); ETTH (code 2); combined EM + ETTH (code $1+$ code 2$)$; and $\mathrm{CDH}$. The combined diagnosis (EM + ETTH) was included in the study in response to ICHD-II recommendations that advise conserving the two headache categories when both are present in the same patient. The CDH group, a diagnosis that is not referenced in the ICHD-II, included patients with CM (code 1.5.1) according to the 2006 criteria (29) as well as those with CTTH (code 2.3). Aura, the reversible focal neurological phenomenon often associated with migraines, was coded as migraine with aura (MwA) (code 1.2).

\section{Measures}

At the first medical appointment, sociodemographic information was recorded including age, sex, grade and school absenteeism. Parents were asked to report absenteeism as the number of school days missed in the preceding year due to headache. Data were then transformed into categories including none, $>7$ days and $>1$ month. It has been shown that there is a strong association between official school records, and parent and adolescent reports of attendance $(30,31)$. The age range for the study allowed patients to be classified into two groups: children (eight to 11 years of age) and adolescents (12 to 17 years of age).

Two psychological tests were used to measure comorbid conditions:

The Revised Children's Manifest Anxiety Scale (R-CMAS) is a scale for evaluating anxiety symptoms. It has been validated and standardized in the French population for children six to 19 years of age (32). The R-CMAS has good reliability and validity $(33,34)$. It is composed of 37 yes/no items that assess the level of generalized anxiety and four subtypes: physiological anxiety, worry/hypersensitivity, social preoccupation/concentration and deceit.

The Multiscore Depression Inventory for Children (MDI-C) is a scale commonly used for evaluating levels of depressive symptoms $(35,36)$. The MDI-C includes 79 yes/no items that sum to a total score corresponding to a general measure of the severity of depression. The items are grouped into eight subscales including low energy, anxiety, self-esteem, sad mood, hopelessness, social introversion, pessimism and provocation. The MDI-C has been standardized and validated in the French population for children eight to 17 years of age (37).

Both the R-CMAS and the MDI-C are considered to be dimensional scales and rely on self-report. Both questionnaires were alternately presented to patients before or after the medical appointment. Patients completed the scales in the presence of a psychologist who was not aware of the headache diagnosis.

The psychological tests were used for two reasons. First, a score could be calculated for the average level of anxiety and depressive symptoms for each headache diagnosis, which could then be compared across headache groups and with standardized scale norms. Second, scores from the two scales could be used to determine whether a patient scored above a clinical threshold, suggesting more serious anxious or depressive tendencies. A threshold score of $\geq 66$ was chosen to represent clinical levels of anxiety or depression. This score corresponds to $5 \%$ on the Gauss curve, which identifies the $5 \%$ of the French pediatric population with the highest scores, reflecting clinically significant anxiety or depression symptoms $(35,36)$. Average scores on the two tests were also compared across categories of patient characteristics such as age, sex, school absenteeism, duration of headache history and presence of aura.

In agreement with the hospital's ethics committee, written consent was obtained from every child and parent/guardian participating in the study before completing the anxiety and depression scales. If a child's score on either psychological test revealed clinical symptom levels, a referral was made for the child and the parents for an evaluation with a staff psychologist.

A second medical consultation occurred three to six months following the first, and provided a confirmation of all diagnoses. According to ICHD-II criteria, 25 subjects were no longer eligible because their diagnosis of primary headache was not confirmed at the follow-up appointment.

\section{Statistical analyses}

Data were analyzed using Student's $t$ tests to compare mean scores, ANOVAs to examine the influence of risk factors on psychiatric comorbidity, a post hoc Tukey test for pairwise comparisons and $\chi^{2}$ tests to compare proportions of 'clinical' anxiety and depression scores; $\mathrm{P}<0.05$ was considered to be statistically significant. A Bonferroni correction was used to account for multiple comparisons. Statistical analyses were conducted using the R program, version 2.5.1 (38).

\section{Descriptive data}

\section{RESULTS}

The final sample consisted of 368 patients (201 girls, 167 boys; ratio $1.2: 1$; mean $[ \pm \mathrm{SD}$ ] age $11.9 \pm 2.3$ years; range eight to 17 years) who 
TABLE 1

Sample characteristics

\begin{tabular}{|c|c|c|c|c|c|}
\hline Characteristic & Total sample & Episodic headache & Chronic daily headache & Chronic migraine & Chronic tension-type headache \\
\hline Total $n$ & 368 & 297 & 71 & $15(21.1)$ & $56(78.9)$ \\
\hline Age, years, mean \pm SD & $11.9 \pm 2.3$ & $11.5 \pm 2.3$ & $11.2 \pm 2.3$ & $10.9 \pm 2.0$ & $11.3 \pm 2.4$ \\
\hline \multicolumn{6}{|l|}{ Age } \\
\hline Children (8-11 years of age) & $197(53.5)$ & $156(52.5)$ & $40(56.3)$ & $8(53.3)$ & $32(57.1)$ \\
\hline Adolescents (12-17 years of age) & $171(46.5)$ & $141(47.5)$ & $31(43.7)$ & $7(46.7)$ & $24(42.9)$ \\
\hline \multicolumn{6}{|l|}{ Sex } \\
\hline Female & $201(54.6)$ & $151(50.8)$ & $50(70.4)$ & $9(60.0)$ & $41(73.2)$ \\
\hline Male & $167(45.4)$ & $146(49.2)$ & $21(29.6)$ & $6(40.0)$ & $15(26.8)$ \\
\hline Headache history, months, mean \pm SD & $39.3 \pm 28.5$ & $39.9 \pm 27.7$ & $36.9 \pm 31.7$ & $24.2 \pm 27.6$ & $40.1 \pm 32.1$ \\
\hline
\end{tabular}

Data presented as $n$ (\%) unless otherwise indicated

TABLE 2

Psychological test scores for the standardized population, and episodic headache and chronic headache samples

\begin{tabular}{|c|c|c|c|}
\hline & Anxiety (R-CMAS) & Depression (MDI-C) & Low energy \\
\hline Standardized population & $50.0 \pm 10.0^{*}$ & $50.0 \pm 10.0^{\dagger \ddagger}$ & $50.0 \pm 10.0^{\text {fी** }}$ \\
\hline Episodic headache $(n=297)$ & $52.2 \pm 11.0^{*}$ & $51.8 \pm 9.2^{\ddagger}$ & $55.0 \pm 9.5^{\text {I㧊 }}$ \\
\hline $\begin{array}{l}\text { Chronic daily headache (>15 days/month; >3 months) } \\
(\mathrm{n}=71)\end{array}$ & $52.3 \pm 10.7$ & $53.1 \pm 8.7^{\dagger}$ & $57.9 \pm 10.5^{\star \star \ddagger \ddagger}$ \\
\hline Chronic migraine $(n=15)$ & $57.7 \pm 11.9 \S \S$ & $59.5 \pm 7.0^{\S}$ & $64.8 \pm 5.7^{\dagger \dagger}$ \\
\hline Chronic tension-type headache $(n=56)$ & $50.8 \pm 10.1 \S \S$ & $51.4 \pm 8.4 \S$ & $56.0 \pm 10.7^{\dagger \dagger}$ \\
\hline
\end{tabular}

Data presented as mean $\pm S D$. ${ }^{*} \neq \$ \uparrow * *++C a t e g o r i e s$ with the same symbols were significantly different at $P<0.001$ according to pairwise $t$ tests; $¥ \pm$ Significantly different at $P<0.05$; $§$ Significantly different at $P=0.03$. MDI-C Multiscore Depression Inventory for Children; R-CMAS Revised Children's Manifest Anxiety Scale

met the inclusion criteria and completed the psychological tests. Sample characteristics are presented in Table 1. In this sample, 297 patients presented with $\mathrm{EH}, 88$ of whom presented with migraine (23.9\%), 19 with tension-type headache (5.2\%), and 190 with migraine and tension headache $(51.6 \%)$. The remaining 71 patients presented with $\mathrm{CDH}(19.3 \%)$.

Among the 71 patients with $\mathrm{CDH}$ (mean age $11.2 \pm 2.3$ years), 56 were diagnosed with CTTH (14.2\% of total, $78.9 \%$ of $\mathrm{CDH})$ and 15 with $\mathrm{CM}$ (3.8\% of total, $21.1 \%$ of $\mathrm{CDH}$ ). Girls were significantly more likely than boys to be in the $\mathrm{CDH}$ group (ratio 2.4:1) whereas in the EH groups, girls and boys were approximately equally represented $\left(\chi^{2}=8.86 ; \mathrm{P}<0.001\right)$ (Table 1$)$. The mean age at first consultation did not differ for $\mathrm{CDH}$ patients compared with the rest of the sample, nor between types of CDH (CTTH and CM) (Table 1). A delay of three years and one month was observed between symptom onset and the first medical consultation for $\mathrm{CDH}$ patients, compared with three years and four months for the rest of the sample (not statistically significant). The time period between symptom onset and first consultation for CM versus CTTH was not statistically significant, although it did reach what could be considered to be clinically significant (CM: two years, two months, versus CTTH: three years, five months; $t[69]=1.70 ; \mathrm{P}=0.09$ ). The age distributions were comparable across all headache diagnoses, as were the distributions for sex, age and headache diagnosis groups between study participants and nonparticipants.

\section{Association of $\mathrm{CDH}$ and psychopathology}

First, regarding depression, the mean level of depressive symptoms was significantly higher for children with $\mathrm{CDH}$ (mean total score = $53.13 \pm 8.75)$ compared with population norms (mean total score $=$ $50.00 \pm 10.00)(t[70]=3.01 ; \mathrm{P}<0.001)$, but did not differ significantly between children with $\mathrm{CDH}$ and children with $\mathrm{EH}$ (Table 2), between children and adolescents, or between girls and boys. However, among $\mathrm{CDH}$ patients, those with $\mathrm{CM}$ had significantly higher mean depression scores than those with CTTH $(t[69]=3.39 ; \mathrm{P}<0.001)$ (Table 2).

Among the 71 patients with $\mathrm{CDH}, 7.0 \%(\mathrm{n}=5)$ had depression scores that were clinically significant, indicating severe symptoms $(\geq 66)$; however, this percentage was not statistically different compared with the standardized population norms $(5.0 \%)$.
Second, regarding anxiety, there was no statistically significant difference observed $(t[70]=1.79 ; \mathrm{P}=0.08)$ between mean levels of anxiety symptoms for $\mathrm{CDH}$ patients (mean total score $=52.28 \pm 10.75) \mathrm{com}$ pared with population norms (mean total score $=50.00 \pm 10.00$ ). Mean symptom levels for anxiety also did not differ significantly between children with $\mathrm{CDH}$ and children with $\mathrm{EH}$ (Table 2), between children and adolescents, or between girls and boys. However, among $\mathrm{CDH}$ patients, those with $\mathrm{CM}$ had significantly higher mean anxiety scores than those with CTTH $(t[69]=2.25 ; \mathrm{P}<0.05)$ (Table 2).

Among patients with $\mathrm{CDH}, 11.3 \%(\mathrm{n}=8)$ had anxiety scores that were clinically significant, indicating severe symptoms $(\geq 66)$. Children with $\mathrm{CDH}$ were more likely to have clinically significant anxiety scores $(\geq 66)$ compared with the standardized population norms $(5.0 \%)$ $\left(\chi^{2}=5.87 ; \mathrm{P}<0.05\right)$.

Psychopathology and headache diagnosis

In the overall sample, an ICHD-II diagnosis (1) of MwA was associated with anxious and depressive symptoms. Children with this diagnosis had significantly higher mean anxiety and depression scores than children not presenting with aura $(54.02 \pm 11.01$ versus $49.21 \pm 10.31, t[347]=4.01, \mathrm{P}<0.001 ; 53.24 \pm 9.17$ versus $50.07 \pm 8.80$, $\mathrm{t}[347]=3.15, \mathrm{P}<0.001$, respectively). Patients experiencing MwA were more likely to have clinically severe anxiety scores $(\geq 66)$ compared with those without aura (OR 3.60 [95\% CI 1.56 to 8.32]). Frequency of headache and duration of headache history were not associated with anxiety $(\mathrm{F}[2,335]=2.19, \mathrm{P}=0.11 ; \mathrm{F}[2,335]=0.48, \mathrm{P}=0.62$, respect ively) or depression $(F[2,335]=0.51, P=0.60 ; F[2,335]=0.94, P=0.39$, respectively)

\section{Functional consequences}

Twice as many children with $\mathrm{CDH}$ compared with children with $\mathrm{EH}$ (46.5\% versus $20.5 \%$ ) had missed at least seven days of school because of their headaches during the academic year preceding the medical consultation $\left(\chi^{2}=18.39 ; \mathrm{P}<0.001\right)$. Children who had missed $>1$ month of school were four times as likely to be in the $\mathrm{CDH}$ group compared with the EH group (16.9\% versus $\left.4.0 \% ; \chi^{2}=15.86 ; \mathrm{P}<0.001\right)$. The mean depression score for $\mathrm{CDH}$ patients was significantly higher among children with at least one month of missed school compared with children with no school absences $(t[35]=2.52 ; \mathrm{P}<0.05)$ (Table 3$)$. 
TABLE 3

School absenteeism according to headache type and comorbidity with anxiety or depression

\begin{tabular}{|c|c|c|c|}
\hline \multirow[b]{2}{*}{ Headache type } & \multirow[b]{2}{*}{ No absenteeism } & \multicolumn{2}{|c|}{ Time absent over the past year } \\
\hline & & $\geq 7$ days & $\geq 1$ month \\
\hline Episodic headache $(n=297)$ & $106(35.7)$ & $61(20.5)$ & $12(4.0)$ \\
\hline Anxiety score, mean \pm SD total score & $49.8 \pm 10.5^{*}$ & $54.5 \pm 10.0^{*}$ & $55.7 \pm 8.4$ \\
\hline Chronic daily headache $(n=71)$ & $25(35.2)$ & $33(46.5)$ & $12(16.9)$ \\
\hline Anxiety score, mean \pm SD total score & $50.7 \pm 9.9$ & $53.0 \pm 10.6$ & $55.4 \pm 10.9$ \\
\hline
\end{tabular}

Data presented as $n(\%)$ unless otherwise indicated. *Significantly different at $P<0.01$ according to pairwise $t$ tests; $t \neq \S$ Significantly different at $P<0.001$

Similar results were found for the overall sample. Youth with high anxiety scores were more likely to have missed school $(77.1 \%$ versus $\left.62.5 \% ; \chi^{2}=3.87 ; \mathrm{P}<0.05\right)$ and the mean depression score was significantly higher among youth with the most school absences (Table 3). None of the patients with $\mathrm{CDH}$ had completely stopped attending school. These children reported lower energy than those with $\mathrm{EH}$ $(t[366]=2.22 ; \mathrm{P}<0.05)$ and those with $\mathrm{EH}$ reported lower energy than the population norm $(t[296]=9.15 ; \mathrm{P}<0.001)$ (Table 2$)$.

\section{DISCUSSION}

Children and adolescents with $\mathrm{CDH}$ were at increased risk for anxiety and the mean level of depressive symptoms were found to be significantly higher than population norms. However, this mean level of depression in $\mathrm{CDH}$ was still well within the average range, and children with $\mathrm{CDH}$ were not more likely to report clinically significant symptoms of depression.

The association between $\mathrm{CDH}$ and anxious and depressive symptoms has been demonstrated in previous studies. For example, in a sample of 143 children, Seshia (39) found that $6 \%$ had clinically significant anxiety symptoms and $9 \%$ had clinically significant depressive symptoms. We found comparable rates of anxiety and depressive symptoms in our sample of children and adolescents with CDH (11.3\% and $7 \%$ ). The rates of anxiety and depression in the standardization sample to which we compared our sample were $5.0 \%$ on average.

In a study involving 59 children with $\mathrm{CDH}$, Galli et al (13) found anxiety to be the most common comorbid psychological problem. This is consistent with our finding that $11.3 \%$ of children had clinically significant anxiety scores compared with $7 \%$ of children with clinically significant depression scores. In a similar study by Moore and Shevell (21), 10\% of the clinical sample, which consisted of youth between seven and 16 years of age, also had anxiety or depressive disorders. However, several other studies among clinical populations found much higher rates of psychological problems associated with $\mathrm{CDH}$, ranging from $46 \%$ to $66 \%(3,13,40)$.

Contrary to our findings that levels of anxiety and depressive symptoms did not differ between children with CDH and those with $\mathrm{EH}$, other studies have found the opposite. Guidetti et al (3), for example, revealed that psychiatric comorbidity was higher among the 19 subjects with CTTH compared with 61 subjects with ETTH ( $87.5 \%$ versus $30.5 \%)$. Raieli et al (2) found similar results in 105 children $<6$ years of age with $80 \%$ of those with $\mathrm{CDH}$ having psychiatric comorbidities compared with $38.4 \%$ in those with tension-type headache. In a recent study, Masruha et al (41) observed that in the CM group the mean score for social phobia was higher than in the EM group. However, the methods for collecting psychological data were different (categorical DSM-IV diagnoses versus dimensional scales with mean score); therefore, it is difficult to make comparisons across these studies.

Among patients with $\mathrm{CDH}$, those with $\mathrm{CM}$ had higher levels of anxious and depressive symptoms than those with CTTH. This difference was expected because CM typically evolves from migraine by an increase in the frequency of migraine episodes (42). Silberstein et al (42) even used the term 'transformed migraine' to describe CM. Epidemiological studies have shown higher levels of psychiatric comorbidity in children with migraine compared with those with a diagnosis of ETTH $(3,43)$. However, three studies using clinical samples found no difference in psychiatric comorbidity between these two groups of $\mathrm{CDH}(12,44,45)$. It is difficult to compare findings across studies when subjects were not diagnosed based on identical criteria or classifications. The earliest studies used ICHD criteria from 1988, whereas more recent studies used the revised criteria from 2004 (1). In addition, some authors $(8,46)$ used the Silberstein classification $(41,47)$ rather than the ICHD-II. Similar to Guidetti et al (3), we did not observe any difference in anxiety and depressive symptoms between girls and boys with $\mathrm{CDH}$.

Our results showed that a diagnosis of MwA was associated with anxious and depressive symptoms and tripled the risk of having severe anxiety symptoms among all children with headache. For the group of children with $\mathrm{CDH}$, there was a similar trend, but the number of children was too small to draw any firm conclusions. This risk factor of MwA has also been highlighted in a recent study, in which the diagnosis of MwA was associated in $64.3 \%$ of cases with at least one psychiatric disorder. This diagnosis also had the highest prevalence and the highest risk of having comorbid psychiatric disorders (15). This result is much higher than what we observed in our sample. This may partly be explained by differences in methodology because their sample came from the general population and consisted of adolescents 12 to 15 years of age, and psychiatric diagnoses were established according to the Diagnostic and Statistical Manual of Mental Disorders, 4th edition (48). However, psychiatric comorbidity appears to increase with age, with the prevalence being much higher in adults with $\mathrm{CDH}$ than in children, ranging from $64 \%$ to $90 \%$ in clinical and general populations $(17,49,50)$. Aura symptoms were also found to be a risk factor for depression in adults with $\mathrm{CDH}$ (51). The association between MwA and psychiatric comorbidity has rarely been studied in children and adolescents. This may be due to the fact that for the diagnosis of CM, according to the ICHD-II criteria (1) and the appendix added in 2006 (29), only the frequency of migraine without aura is taken into account, not that of MwA.

Girls were twice as likely $(70.4 \%)$ to experience CDH. These results are comparable with other studies that have focused on subjects with $\mathrm{CDH}$ in clinical populations of this age group (eight to 17 years), such as research by Koenig et al (11) (70\% girls), Hershey et al (52) (68\% girls) and Pakalnis et al (7) (70\% girls). In contrast, for children with $\mathrm{EH}$, the number of girls $(50.8 \%)$ was equivalent to the number of boys. In a study by Seshia (39), 65\% of CDH patients and $46 \%$ of patients with $\mathrm{EH}$ were girls.

CTTH was the most frequent diagnosis in our cohort. It was the diagnosis for $78.9 \%$ of patients, followed by CM (21.1\%). No patient in our study presented with new daily persistent headache or hemicrania continua, the latter being rare in children (53). In a recent study on $\mathrm{CDH}$ in the general population, the latter two diagnoses were also absent (24).

Three studies have also found a higher prevalence of CTTH than CM $(7,54,55)$. Depending on which diagnostic criteria are used (Silberstein's or the ICHD-II) and the version, the distribution of diagnostic categories and patients affected by them differs greatly. Several authors $(13,18,39)$, responding to the clinical experience that CTTH and CM frequently co-occur, have used a dual diagnosis 
referred to as the 'mixed syndrome' or 'comorbid pattern' by Gladstein and Holden (44). It corresponds to the category that includes comorbid CM and CTTH. This mixed syndrome is not included in the ICHD-II. In our study, we did not include a 'mixed syndrome' diagnosis. The main reason for this was that the criteria for the CM diagnosis were recently reviewed by the Headache Classification Committee. The previous criteria were very restrictive, which meant that very few patients received the diagnosis of $\mathrm{CM}$. The new criteria for defining CM adopted in the 2006 appendix state that CM can be diagnosed when headache (tension-type headaches and/or migraine) is present at least 15 days per month for at least three months (29). This most recent version now allows the inclusion of some of the patients who had previously received a 'dual diagnosis' to now be diagnosed with CM, which is what was applied in the present study but was not possible in studies published before 2006.

The two aspects of quality of life evaluated in the present study were school absenteeism and low energy. Children with $\mathrm{CDH}$ were significantly more likely to experience low energy than children with $\mathrm{EH}$. In a study involving adults, low energy was reported on at least eight days per month by patients with $\mathrm{CDH}$ (56). This result is difficult to explain using a simple pathophysiological perspective. It may be related to the impact of $\mathrm{CDH}$ on the lives of children and associated with psychiatric symptoms. Surprisingly, despite the frequency of headache reported here, no child in the sample had completely stopped attending school, contrary to the findings of Wang et al (18), who found that $6 \%$ of subjects had left school, and Wiendels et al (22), who found that $9 \%$ had stopped attending school. However, children with $\mathrm{CDH}$ in our study were out of school more often and for longer periods because of their headaches than children with EH. Among those who experienced anxiety symptoms, it was rare to have never been absent from school. Depression scores were associated with elevated school absenteeism as well. Breuner et al (19), in a study involving a population of adolescents, also found that those who missed the most school because of their headaches had higher depression scores. Our results showed a trend in this direction, with the mean scores of anxiety and depression increasing with increasing days of school missed. It would be overly simplistic to explain these results in a linear fashion in which anxiety and CDH are responsible for school absenteeism. The link between psychological problems, $\mathrm{CDH}$ and truancy is complex, and causal relationships cannot be determined from the present research

\section{REFERENCES}

1. Headache Classification Subcommittee of the International Headache Society. The International Classification of Headache Disorders, 2nd edn. Cephalalgia 2004:24:9-160.

2. Raieli V, Eliseo M, Pandolfi E, et al. Recurrent and chronic headaches in children below 6 years of age. J Headache Pain 2005;6:135-42.

3. Guidetti V, Galli F, Fabrizi P, et al. Headache and psychiatric comorbidity: Clinical aspects and outcome in an 8-year follow-up study. Cephalalgia 1998;18:455-62.

4. Sillanpää M, Piekkala P, Kero P. Prevalence of headache at preschool age in an unselected child population. Cephalalgia 1991;11:239-42.

5. Wang SJ, Fuh JL, Lu SR, Juang KD. Outcomes and predictors of chronic daily headache in adolescents: A 2-year longitudinal study. Neurology 2007;68:591-6.

6. Chong SC, Chan YH, Ong PS, Low PS, Tay SK. Headache diagnosis, disability and co-morbidities in a multi-ethnic, heterogeneous paediatric asian population. Cephalalgia 2010;30:953-61.

7. Pakalnis A, Butz C, Splaingard D, Kring D, Fong J. Emotional problems and prevalence of medication overuse in pediatric chronic daily headache. J Child Neurol 2007;22:1356-9.

8. Cuvellier JC, Couttenier F, Joriot-Chekaf, S, Vallée L. Chronic daily headache in French children and adolescents. Pediatr Neurol 2008;38:93-8.

9. Seshia SS, Wang SJ, Abu-Arafeh I, et al. Chronic daily headache in children and adolescents: A multi-faceted syndrome. Can J Neurol Sci 2010;37:769-78.
Our study had several limitations, some of which were mentioned above. Patients were recruited in a specialized medical centre, which means there was a selection bias of the sample and the results should not be generalized to the general population. In addition, the sample size - particularly for CM $(n=15)$ - limits the extent of our conclusions. Moreover, we used self-report measures to assess anxiety and depression, meaning that only the severity of self-reported symptoms was assessed and not genuine psychiatric diagnosis. Finally, although it has been previously shown that teachers, parents and children generally agreed on the number of days of school missed $(30,31)$, no official data from schools were obtained to verify that information.

Despite these limitations, in addition to the typical limitations associated with clinical population studies, our results showed an association between anxiety and depression and $\mathrm{CDH}$ in children and adolescents, with aura being the most important risk factor. Moreover, there was a significant impact of this association on children's school absenteeism.

The information presented in the current study should set the stage for future research endeavours including studies investigating the psychiatric comorbidity in children with $\mathrm{CDH}$ using categorical measures and larger sample sizes to confirm the findings of the present study. Studies of psychological factors that may influence school attendance and functioning, especially in $\mathrm{CDH}$ children, should be developed. An additional area for future research may be the role of parent and family factors in children with $\mathrm{CDH}$ compared with EH.

Psychiatric comorbidity is considered to play a major role in patients with $\mathrm{CDH}$, especially in children, when it is associated with the onset of headache but also with increasing severity and duration of the condition. These factors should be considered to be targets for treatment in efforts to prevent $\mathrm{CDH}$ and especially its duration into adulthood. Primary CDH should be treated with a biopsychosocial approach because of the complexity of the diagnosis and its potential to co-occur with psychological problems.

GRANTS: This study was supported in part by a grant from the Fondation de France.

INSTITUTION: Hôpital Armand Trousseau, Centre de la migraine de l'enfant, 26 Avenue du docteur Arnold Netter, 75571 Paris Cedex 12, France.

10. Hershey AD, Gladstein J, Winner P. Chronic daily headache in the pediatric population. Current Treat Options Neurol 2007;9:14-22.

11. Koenig MA, Gladstein J, McCarter RJ, Hershey AD, Wasiewski W; Pediatric Committee of the American Headache Society. Chronic daily headache in children and adolescents presenting to tertiary headache clinics. Headache 2002;42:491-500.

12. Esposito SB, Gherpelli JL. Chronic daily headaches in children and adolescents: A study of clinical characteristics. Cephalalgia 2004;24:476-82.

13. Galli F, Patron L, Russo PM, et al. Chronic daily headache in childhood and adolescence: Clinical aspects and a 4-year follow-up. Cephalalgia 2004;24:850-8.

14. Slater SK, Kashikar-Zuck SM, Allen JR, et al. Psychiatric comorbidity in pediatric chronic daily headache. Cephalalgia 2012;32:1116-22.

15. Wang SJ, Juang KD, Fuh JL, Lu SR. Psychiatric comorbidity and suicide risk in adolescents with chronic daily headache. Neurology 2007;68:1468-73.

16. Breslau N, Davis GC, Andreski P. Migraine, psychiatric disorders, and suicide attempts: An epidemiologic study of young adults. Psychiatry Res 1991;37:11-23.

17. Verri AP, Cecchini AP, Galli C, Granella F, Sandrini G, Nappi G. Psychiatric comorbidity in chronic daily headache. Cephalalgia 1998;18:45-9.

18. Wang SJ, Fuh JL, Lu SR, Juang KD. Chronic daily headache in adolescents: Prevalence, impact, and medication overuse. Neurology 2006;66:193-7. 
19. Breuner CC, Smith MS, Womack WM. Factors related to school absenteeism in adolescents with recurrent headache. Headache 2004:44:217-22.

20. Powers SW, Patton SR, Hommel KA, Hershey AD. Quality of life in childhood migraines: Clinical impact and comparison to other chronic illnesses. Pediatrics 2003;112:1-5.

21. Moore AJ, Shevell M. Chronic daily headaches in pediatric neurology practice. J Child Neurol 2004;19:925-9.

22. Wiendels NJ, Van der Geest MC, Neven AK, Ferrari MD, Laan LA. Chronic daily headache in children and adolescents. Headache 2005;45:678-83.

23. Canestri P, Galli F, Guidetti V, Tomaciello A. Chronic daily headache $(\mathrm{CDH})$ in children and adolescents: A 2 year follow-up study. Cephalalgia 2001;21:288.

24. Arruda MA, Guidetti V, Galli F, Albuquerque RC, Bigal ME. Primary headaches in childhood - a population-based study. Cephalalgia 2010;30:1056-64.

25. Solomon S, Lipton RB, Newman LC. Clinical features of chronic daily headache. Headache 1992;32:325-9.

26. Srikiatkhachorn A, Phanthumchinda K. Prevalence and clinical features of chronic daily headache in a headache clinic. Headache 1997:37:277-80.

27. Mack KJ, Hershey AD. Chronic daily headache in adolescence: A continuing problem. Neurology 2009;73:412-3.

28. Charles JA, Peterlin BL, Rapoport AM, Wang SJ, Fuh JL, Lu SR. Chronic daily headache in adolescents: An 8-year follow-up study. Neurology 2010;74:780-1.

29. Headache Classification Committee, Olesen J, Bousser MG, et al. New appendix criteria open for a broader concept of chronic migraine. Cephalalgia 2006;26:742-6.

30. Kearney C. Forms and funtions of school refusal behavior in youth: An empirical analysis of absenteeism severity. J Child Psychol Psychiatry 2007;48:53-61.

31. Logan DE, Simons LE, Stein MJ, Chastain L. School impairment in adolescents with chronic pain. J Pain 2008;9:407-16.

32. Castro D. [Revised Children's Manifest Anxiety Scale (R-CMAS)]. Paris: Editions du Centre de Psychologie Appliquée, 1999a.

33. Reynolds CR, Richmond BO. What I think and feel: A revised measure of children's manifest anxiety. J Abnormal Child Psychol 1978;6:271-80.

34. Reynolds CR, Richmond BO. Manual for the Revised Children's Manifest Anxiety Scale. Los Angeles: Western Psychological Services, 1985.

35. Berndt DJ. Multiscore Depression Inventory (MDI) Manual. Los Angeles: Western Psychological Services, 1986.

36. Kaiser CF, Middaugh SJ, Kee WG, Levin RB, Berndt SM. Self-reported depression profiles in chronic pain and family practice patients. Clin J Pain 1990;6:271-5.

37. Castro D. [Multiscore Depression Inventory for Children (MDI-C)]. Paris: Editions du Centre de Psychologie Appliquée, 1999b.

38. R Development Core Team. R: A Language and Environment for Statistical Computing. Vienna: R Foundation for Statistical Computing Edition, 2008.
39. Seshia SS. Chronic daily headache in children and adolescents. Can J Neurol Sci 2004;31:319-23.

40. Holden EW, Gladstein J, Trulsen M, Wall B. Chronic daily headache in children and adolescents. Headache 1994;34:508-14.

41. Masruha MR, Lin J, Minett TS, et al. Social anxiety score is high in adolescents with chronic migraine. Pediatr Int 2012;54:393-6.

42. Silberstein SD, Lipton RB, Solomon S, Mathew N. Classification of daily and near-daily headaches: Proposed revisions to the IHS criteria. Headache 1994;34:1-7.

43. Merikangas KR, Merikangas JR, Angst J. Headache syndromes and psychiatric disorders: Association and familial transmission. J Psychiatr Res 1993;27:197-210.

44. Gladstein J, Holden EW. Chronic daily headache in children and adolescents: A 2-year prospective study. Headache 1996;36:349-51.

45. Chakravarty A. Chronic daily headache in children and adolescents: A clinic based study from India. Cephalalgia 2005;25:795-800.

46. Vazquez-Delgado E, Schmidt JE, Carlson CR, DeLeeuw R, Okeson JP. Psychological and sleep quality differences between chronic daily headache and temporomandibular disorders patients. Cephalalgia 2004;24:446-54.

47. Silberstein SD, Lipton RB, Sliwinski M. Classification of daily and near-daily headaches: Field trial of revised IHS criteria. Neurology 1996;47:871-5.

48. American Psychiatric Association. Diagnostic and Statistical Manual of Mental Disorders: DSM-IV, 4th edn. Washington, DC: American Psychiatric Association, 1994.

49. Juang KD, Wang SJ, Fuh JL, Lu SR, Su TP. Comorbidity of depressive and anxiety disorders in chronic daily headache and its subtypes. Headache 2000;40:818-23.

50. da Silva A Jr, Costa EC, Gomes JB, et al. Chronic headache and comorbibities: A two-phase, population-based, cross-sectional study. Headache 2010;50:1306-12.

51. Mitsikostas DD, Thomas AM. Comorbidity of headache and depressive disorders. Cephalalgia 1999;19:211-7.

52. Hershey AD, Powers SW, Bentti AL, LeCates S, deGrauw TJ. Characterization of chronic daily headaches in children in a multidisciplinary headache center. Neurology 2001;56:1032-7.

53. Cuvellier JC, Couttenier F, Auvin S, Vallée L. The classification of chronic daily headache in French children and adolescents: A comparison between the second edition of the International Classification of Headache Disorders and Silberstein-Lipton criteria. Neuropsychiatr Dis Treat 2008;4:263-7.

54. Seshia SS, Phillips DF, Von Bayer CR. Childhood chronic daily headache: A biopsychosocial perspective. Dev Med Child Neurol 2008;50:541-5.

55. Scalas C, Calistri L. Chronic daily headache in a paediatric headache centre. J Headache Pain 2005;6:274-6.

56. Holroyd KA, Stensland M, Lipchik GL, Hill KR, O'Donnell FS, Cordingley G. Psychosocial correlates and impact of chronic tension-type headaches. Headache 2000;40:3-16. 


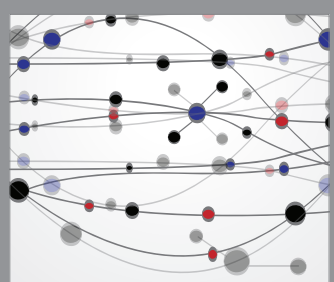

The Scientific World Journal
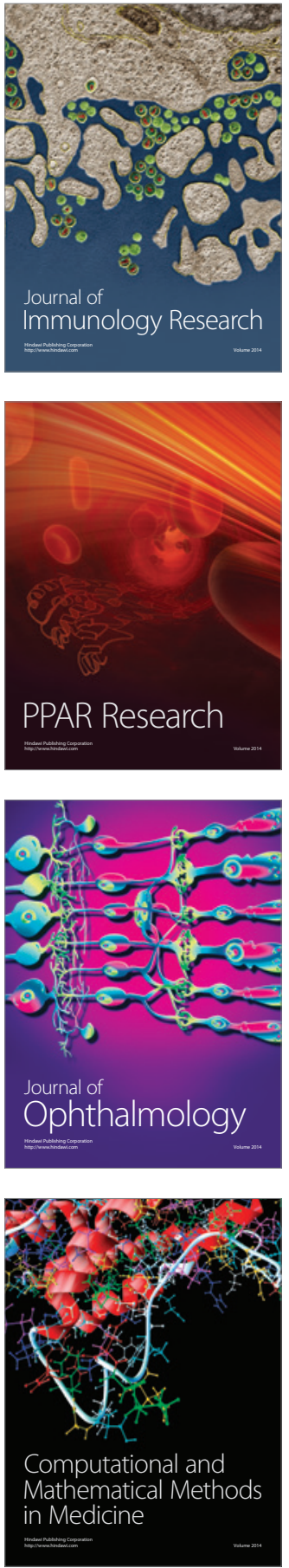

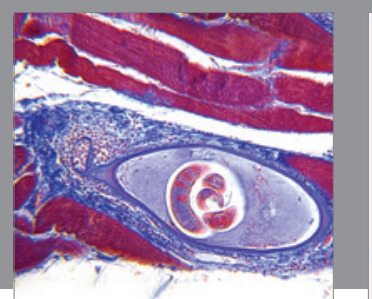

Gastroenterology Research and Practice

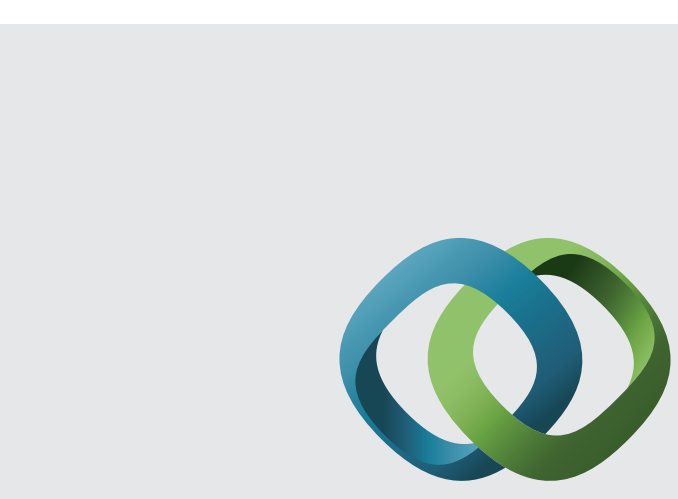

\section{Hindawi}

Submit your manuscripts at

http://www.hindawi.com
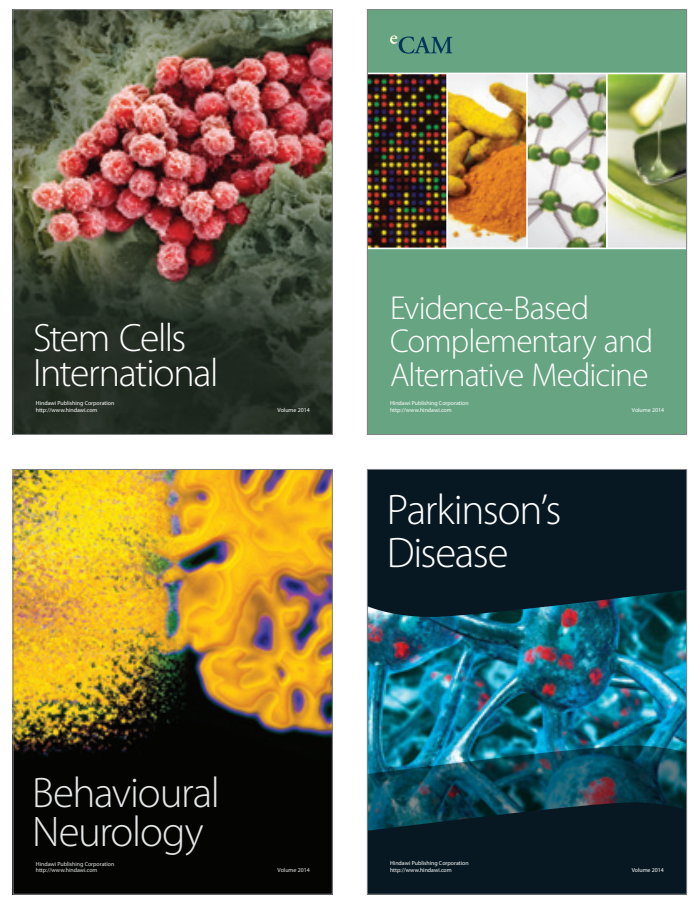
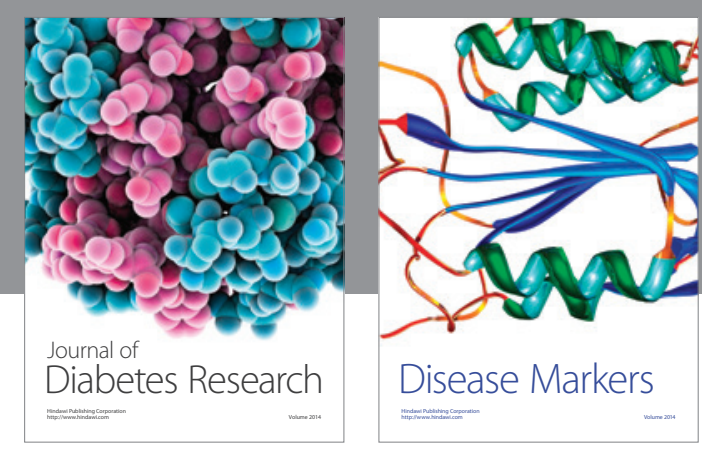

Disease Markers
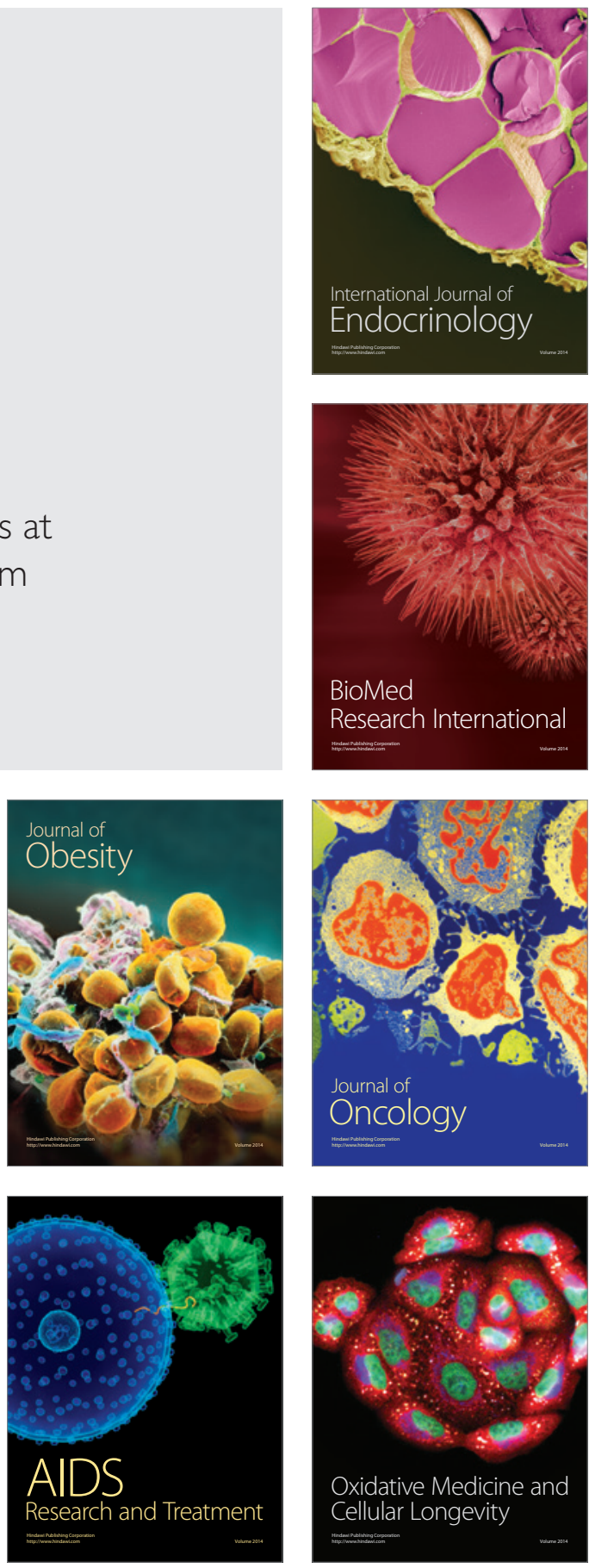